\title{
Minimum Time Allowed in Planned Assessment Interval
}

National Cancer Institute

\section{Source}

National Cancer Institute. Minimum Time Allowed in Planned Assessment Interval. NCI

Thesaurus. Code C117301.

The lower limit in time of a planned period of time between planned assessments. 